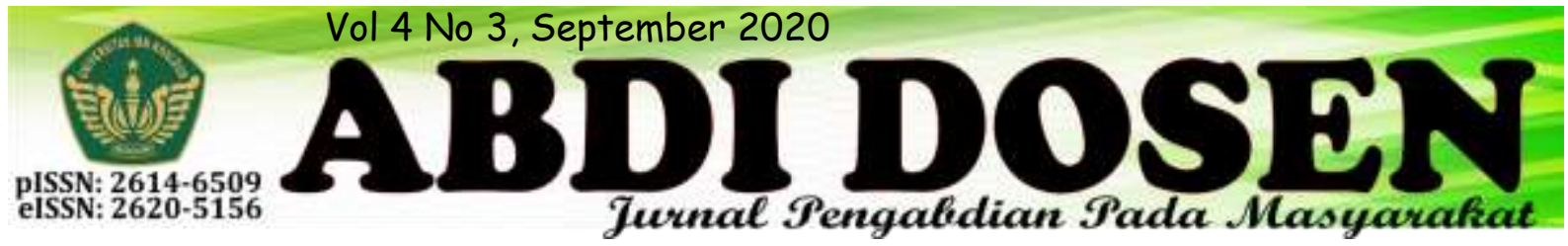

\title{
MENGABDI DAN MELAYANI MASYARAKAT MELALUI KKN DIDESA PASIR MUNCANG KABUPATEN BOGOR
}

\author{
M. Imam Sudarta, Moch. Obby Firdaus \\ imam@uika-bogor.ac.id ${ }^{1}$ \\ moch.obby@gmail.com ${ }^{2}$
}

Dosen Fakultas Ekonomi dan Bisnis Universitas Ibn Khaldun Bogor ${ }^{1}$, Mahasiswa KKN Kelompok 71 Tahun $2016^{2}$

\begin{abstract}
ABSTRAK
Mahasiswa sebagai elemen perguruan tinggi sekaligus generasi muda yang dibekali intelektualitas, memiliki tanggung jawab melaksanakan hal tersebut. Sehingga mahasiswa dijuluki sebagai "agent of change". Dalam KKN mahasiswa belajar mengaitkan antara dunia akademik-teoritik dengan dunia empirik-praktis bagi pemecahan permasalahan agar masyarakat mampu memberdayakan dirinya untuk menolong diri mereka sendiri. Kuliah Kerja Nyata Terintegrasi yang dilaksanakan oleh mahasiswa UIKA Bogor bertempat di Kp. Dukuh RW 06 Desa Pasir Muncang Kec. Caringin Kab. Bogor selama \pm 1,5 bulan yang melibatkan mahasiswa dari berbagai fakultas dan jurusan dan sebagian besar program kerja yang dilaksanakan terkait dengan bidang ilmu yang dimiliki oleh tiap-tiap mahasiswa.
\end{abstract}

Kata Kunci : Mengabdi, Melayani, Program Masyarakat.

\section{PENDAHULUAN}

Berikut adalah gambaran umum Desa Pasir Muncang Kecamatan Caringin Kabupaten Bogor yang menjadi lokasi KKN Terintegrasi Kelompok 71 yang merupakan hasil dari survey yang telah kami laksanakan pada hari 26 juli 2016. Sebagian besar yang kami dapatkan merupakan hasil wawancara kami dengan Bapak Supriatna selaku BPD Desa dan Bapak Deni aparat desa Pasir Muncang. Selain itu, data berikut merupakan hasil pengamatan selama di lokasi sasaran.

1. Luas Desa

2. Batas Wilayah
a. Utara
Duhur
b. Selatan
c. Barat Muara Jaya
d. Timur
Duhur
: Ds. Lemah
: Ds. Tangkil
: Jl. Provinsi /
: Ds. Lemah

: $195 \mathrm{H}$

3. Kependudukan

a. Kepala Keluarga : 2.046 KK
b. Jenis Kelamin
: 3.889 Jiwa
c. Perempuan
: 3.888 Jiwa
d. Total
: 7.777 Jiwa

Dari data diatas diperoleh tingkat kepadatan penduduk rata-rata 225 jiwa/km. Wilayah sasaran RW 06 Desa Pasir Muncang Kec. Caringin Kab. Bogor. Wilayah sasara pelaksanaan KKN Terintegrasi 2016 UIKA Bogor yang direkomendasikan berada di RW 06 RT 01,02 dan 03 Kampung Dukuh Desa Pasir Muncang Kec. Caringin Kab. Bogor.

Kelembagaan Masyarakat Tingkat RW Kelembagaan masyarakat tingkat RW maupun tingkat RT terlihat masih banyak yang belum berjalan secara efektif. Seperti Karang Taruna, LKM (Lembaga Keuangan Masyarakat), PKBM (Pusat Kegiatan Belajar Masyarakat) dan lembaga kursus sampai saat ini masih belum berjalan sesuai apa yang diharapkan. 
Kondisi Keluarga

Umumnya warga berprofesi sebagai buruh, petani, peternak, tukang ojeg tetapi ada beberapa warga yag bekerja di dinas pertahanan, telkom, membuka home industry dan membuat hasil cemilan lalu di jual di warung.

Bidang Pendidikan

Di bidang pendidikan warga kampung Dukuh RW 06 Desa Pasir Muncang ini pada umumnya merupakan lulusan SD, SMP atau SMA. Hal ini dikarenakan faktor ekonomi yang masih dalam taraf menengah kebawah. Selain itu adanya budaya setelah lulus sekolah tingkat SMP/SMA bekerja dan kemudian menikah. Namun telah terdapat PAUD yang masih perlu tambahan fasilitas untuk memperlancar proses belajar mengajar. Selain itu masih banyak bidang pendidikan kampung Dukuh yang berjalan belum efektif.

Bidang Lingkungan dan Keluarga Bergizi

Berdasarkan informasi yang didapat dari aparatur desa masyarakat Kp. Dukuh RW 06 Pasir Muncang memiliki lingkungan yang bersih dan terawat tetapi belum terdapatnya tempat sampah besar untuk menampung semua sampah warga, keluarga bergizi masyarakat kampung Dukuh keluarga sehat yang menggunkkan pola hidup sehat.

\section{METODE PENGABDIAN}

Dalam pelaksanaan Program Kerja KKN Terintegrasi Kelompok 71 Universitas Ibn Khaldun-Bogor di Desa Caringin Kp. Dukuh Rt 02/06 menggunakan metode pendekatan Participatory Rural Appraisal (PRA), yaitu metode yang melibatkan masyarakat mulai dari tahap perencanaan, pelaksanaan, pemanfaatan dan evaluasi. Metode PRA ini bertujuan untuk menghasilkan rancangan program yang relevan dengan harapan dan keadaan masyarakat, agar juga diharapkan kemampuan masyarakat dalam menganalisa keadaan mereka sendiri dan diwujudkan dengan melakukan perencanaan dan realisasi dapat berkembang, sehingga dapat membuat program dan melaksanakannya. Dalam kegiatan PRA ini mahasiswa hanya sebagai fasilitator sekaligus motivator dan masyarakatlah sebagai pelaksananya.

Adapun teknik dari PRA (Participatory Rural Appraisal) itu sendiri adalah:

1. Pendekatan Participatory Rural Appraisal (PRA).adalah (Pengkajian Pedesaan Secara Partisipatif).

2. Pendekatan tersebut memungkinkan masyarakat desa saling membagi, menambah dan menganalisis pengetahuan tentang kondisi kehidupannya dalam rangka membuat perencanaan dan tindakan.

3. Dengan demikian Metode PRA adalah cara yang digunakan dalam melakukan kajian untuk memahami keadaan atau kondisi desa dengan melibatkan partisipasi masyarakat. Atau Pengkajian/Penilaian (keadaan) Desa Secara Partisipatif.

4. Pemberdayaan Masyarakat dan Partisipasi merupakan strategi dalam paradigma pembangunan yang berpusat pada rakyat.

5. Menjalin kerjasama dengan masyarakat desa Caringin Kp. Dukuh Rt 02/06 dalam pelaksanaan program kerja yang ada.

6. Bekerjasama dengan aparat Desa untuk pelaksanaan program kerja 


\section{REALISASI PROGRAM}

\section{Bidang Pendidikan}

a. Mengajar di PAUD cempaka

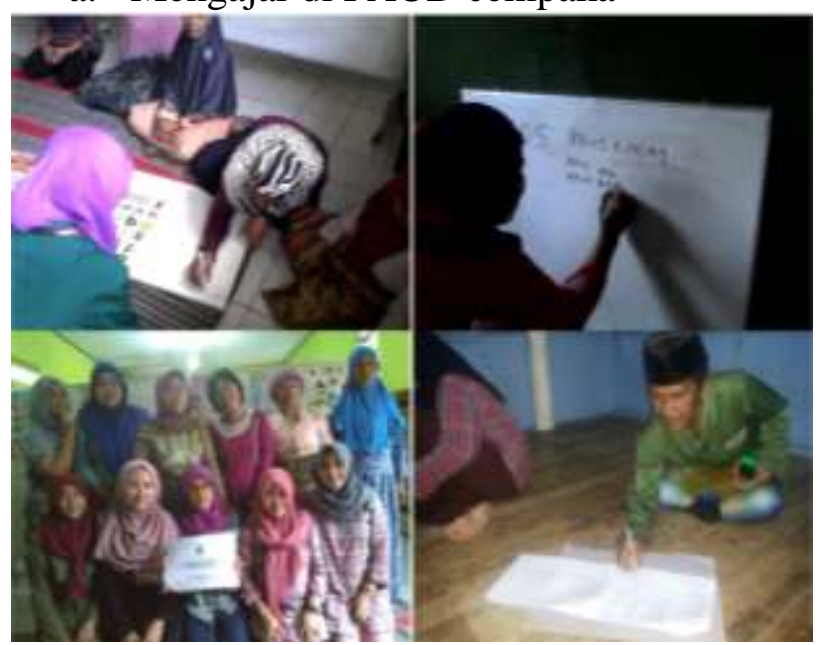

b. Keaksaraan Fungsional (KF)

c. Mengajar di SDN Pasir Muncang 01 dan 02

d. Taman Baca Masyarakat

e. Penyuluhan Peran Serta Orang Tua dalam Mendidik Anak Sejak Dini

f. Bimbingan Belajar Pendidikan Agama Islam (PAI)

g. Bimbingan Belajar Bahasa Inggris

h. Bimbingan Belajar Matematika

i. Kursus Komputer

\section{Ekonomi Kreatif}

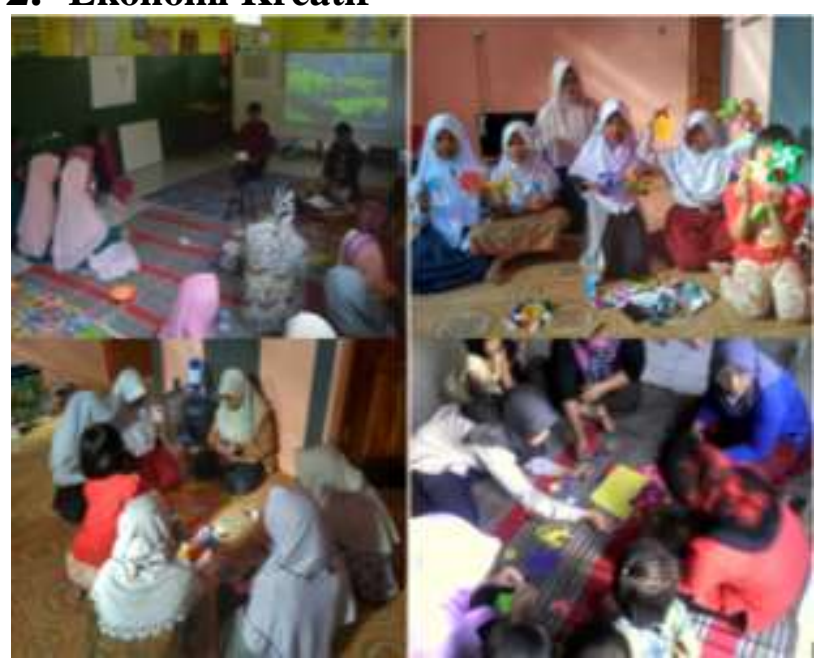

a. Penyuluhan Motivasi Kewirausahaan dan Pemasaran Olah Rumah Tangga
b. Pembuatan Bros dari Kain Perca / Planel
c. Pembuatan Nuget Singkong
d. Bazar Baju bekas Layak Pakai

\section{Bidang Lingkungan}

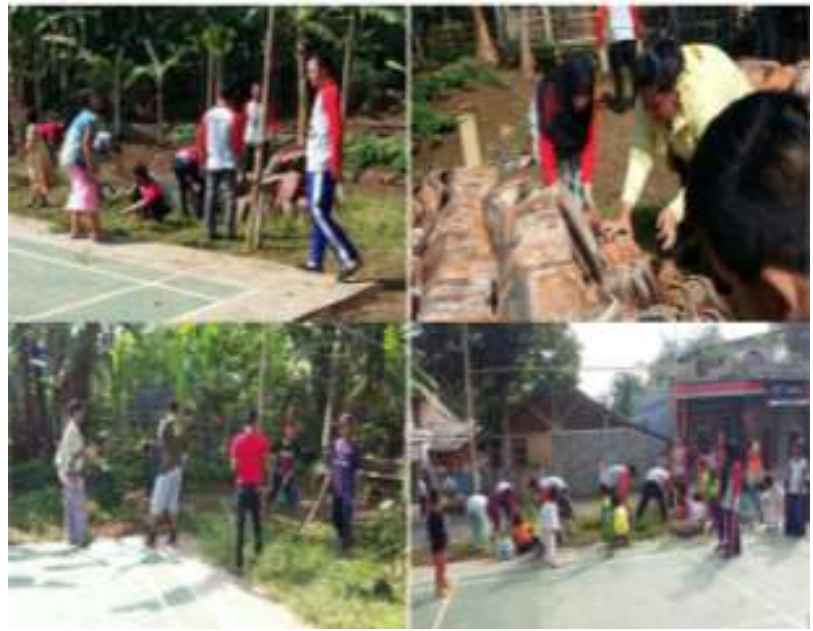
a. Kerja Bakti Mingguan
b. Pembuatan Plang dan Nama Gang

\section{Bidang Lingkungan}

a. Senam Mingguan

b. Penyuluhan PHBS

c. Demonstrasi Cuci Tangan yang Baik dan Benar

d. Demonstrasi Menggosok Gigi yang Benar

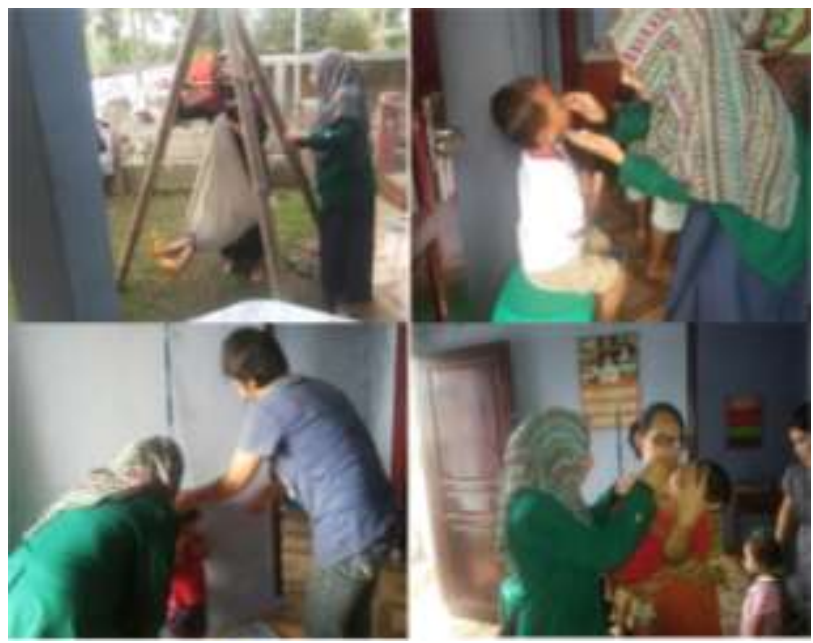

e. Posyandu 


\section{KESIMPULAN}

Tidak bisa dipungkiri lagi bahwa dalam pelaksanaannya, KKN di Kampung ini mengalami berbagai macam kendala. Namun, dengan adanya semangat tinggi dari para peserta KKN dan dukungan baik dari warga, semua kendala tersebut dapat teratasi. Harapan kami semoga berbagai macam kegiatan dicatat sebagai amal baik kami selaku anggota KKN dan hasil - hasil yang sudah dicapai dapat memberikan manfaat bagi agama,nusa dan bangsa khususnya bagi para warga Kp. Dukuh Desa Pasir Muncang.

\section{DAFTAR PUSTAKA}

Kementrian Kesehatan RI. 2011. Pedoman Pembinaan Perilaku Hidup Bersih dan Sehat (PHBS). Jakarta: Kementrian Kesehatan RI.

Prasetya, E, Suarman. (2016). The Effect of Students' Perception on School Environment and Self-discipline towards Their Achievement in Learning English: A Survey at a Private Vocational School in Bogor. education 18 (1), 18

Prasetya, E. (2018). Pemberdayaan Masyarakat Tentang Kesehatan, Pendidikan dan Kreatifitas. Abdi Dosen: Jurnal Pengabdian Pada Masyarakat 2 (1), 19-25.

Priyanto, Sugeng dkk. 2008. Contextual Teaching and Learning Pendidikan Kewarganegaraan Sekolah Menengah Pertama/Madrasah Tsanawiyah Kelas IX Edisi 4. Jakarta: Pusat Perbukuan Departemen Pendidikan Nasional.

Sundarta, M Imam, Melati, Pitri, 2013, Penerapan Metode Just In Time Terhadap Sediaan Bahan Baku Dalam

\section{SARAN DAN REKOMENDASI}

Dari program yang telah direncanakan ada program yang belum terlaksana, hal ini karena adanya beberapa faktor yang tidak mendukung yang sudah dijelaskan sebelumnya di laporan dan bukan berarti cukup sampai disini. Diharapkan kepada angkatan selanjutnya dapat melaksanakan dan menyempurnakan program yang belum terlaksana dan diharapkan juga agar masyarakat di Kp. Dukuh Kelurahan Pasir Muncang dapat membantu dalam program KKN yang sedang dijalani oleh mahasiswa dan mahasiswi agar dapat mencapai tujuan program yang maksimal.

\section{Rangka Meningkatkan Efisiensi Biaya Produksi Pada PT. Cipta Sarana Kenayu Lestari, Hal : 15-35}

Soewartoyo dan Toni Soetopo. 2009. Potensi Sumber Daya Alam Dan Peningkatan Kualitas Sumber Daya Manusia Di Kawasan Massyarakat Pesisir. Kabupaten Bangka. Peneliti Pada Pusat Penelitian Kependudukan Lembaga Ilmu Pengetahuan Indonesia (PPK-LIPI) Vol. IV, No. 2, 2009.

Setianingsih, A. Dkk. (2015). Laporan Kelompok Kuliah Kerja Nyata (KKN). Universitas Negeri Yogyakarta. 